\title{
O CBC E A SOBRADPEC
}

\section{Edmundo Machado Ferraz}

Presidente do CBC (gestão 2008-2009)

Em 29 de julho de 1929 foi fundado no Rio de Janeiro, por um grupo de 49 cirurgiões cariocas o Colégio Brasileiro de Cirurgiões, hoje a maior entidade cirúrgica da América Latina. No XXVIII Congresso Brasileiro de Cirurgia realizado em 26 a 30/7/2009 no Anhembi em São Paulo celebramos os 80 anos de fundação do CBC.

Neste evento realizou-se a $1^{a}$ reunião dos Presidentes das Sociedades Cirúrgicas filiadas a AMB com o objetivo de aproximarmos nossas Sociedades, sairmos de um isolamento histórico que se iniciou na década de 70 para retomarmos o caminho do dialogo, do entendimento, da identificação dos nossos problemas comuns que permitissem retomar nossa identidade e força política para atuarmos como uma Federação em defesa de nossos interesses aviltados por decisões unilaterais de Empresas de Seguro Saúde e também do poder público que não prioriza saúde ou educação como necessidades fundamentais do povo brasileiro. Mais de 15 Sociedades Cirúrgicas participaram de 4 reuniões realizadas na sede da AMB em São Paulo estando novas reuniões programadas para o ano de 2010.

Em outubro de 2009 tivemos o Congresso da SOBRADPEC no Auditório do CBC no Rio de Janeiro.

A SOBRADPEC, Sociedade Brasileira para o Desenvolvimento da Pesquisa em Cirurgia, fundada por Saul Goldenberg e um grupo de cirurgiões pesquisadores brasileiros foi solenemente instalada em 17/9/1987 e formada com o objetivo de tornar-se a Casa do Cirurgião Pesquisador e do Cirurgião Acadêmico.

A Sociedade já dispunha de sua revista a ACTA CIRÚRGICA BRASILEIRA também fundada por Saul Goldenberg e outros pesquisadores no ano anterior em São Paulo.

A Acta é o único periódico latino-americano da área de pesquisa cirúrgica e um dos poucos do mundo, tendo tido uma ascensão meteórica fundamentada em seu valor e importância em pouco mais de 20 anos.

Indexada no Web of Science em 2008 e após um período "incubatório" no Web deverá ser indexada no Journal of Citation of Report que publica os fatores de impacto dos periódicos.

Ocupa o $10^{\circ}$ lugar dos 220 periódicos mais listados na SciELO (julho de 2009). Nasceu da necessidade da publicação das Teses de Mestrado e Doutorado do Curso de Pós Graduação em Técnica Operatória e Cirúrgica Experimental da Escola Paulista de Medicina. Tornando-se veiculo de publicação da Pós Graduação da EPM. Seu $1^{\circ}$ vol data de 1986 (jan/mar).

No mesmo ano passou a receber artigos de outras instituições e publicou o $1^{\circ}$ suplemento que relatava o $1^{\circ}$ Encontro dos Coordenadores da Pós Graduação em Cirurgia no Brasil com apoio da CAPES presidido por Saul Goldenberg.
Em 1987 foi indexada no LILACS (Index Medico Latino Americano). No seu $5^{\circ}$ ano de existência, 45\% dos artigos eram oriundos de outras instituições, $15 \%$ da EPM e $64 \%$ eram dedicados à cirurgia experimental. Em abril de 2009 atingiu o grau de impacto de 0,1957 .

Ao saudar a SOBRADPEC e sua Diretoria no XI Congresso Brasileiro de Cirurgia Experimental em outubro passado, na Casa do Cirurgião Brasileiro, na sede do CBC no Rio de Janeiro como Presidente desta entidade pude admirar no Auditório as presenças de Saul Goldenberg, Alcino Lazaro da Silva, Alberto Goldenberg, Ernani Aboim, Alberto Schanaider, Edna Frasson de Souza Monteiro e tantos outros, todos membros da Direção da SOBRADPEC e também membros Titulares e Eméritos do CBC.

Nesta ocasião, saudando a todos, proclamei em meu discurso: "O CBC quer também ser a casa da SOBRADPEC. Venham juntar-se a nós, temos muito a fazer pela cirurgia brasileira".

SOMAR sempre foi a palavra mágica entoada por Saul Goldenberg.

Uma corrente de emoção enlaçou os objetivos das duas entidades nessa sessão.

Foi um dos gestos largos e lúcidos da gestão 2008-2009.

Encerrada a Sessão Solene de instalação já havia decidido propor ao Diretório Nacional do CBC a criação da Comissão Especial Permanente de Pesquisa e Cirurgia Experimental o que foi amplamente aceita por Alberto e Saul Goldenberg e toda Direção da SOBRADPEC.

Durante a Reunião do Diretório Nacional foi proposto e aprovado que a SOBRADPEC viesse integrar com sua Diretoria a nossa Comissão Permanente de Pesquisa e Cirurgia Experimental.

Comunicado ao Conselho Superior reunido no dia 5/11/09 surgiu a proposta de ex-Presidentes de que a Diretoria da SOBRADPEC viesse integrar-se ao CEPESQ, Centro de Pesquisa do CBC constante do Estatuto (art. 71) ligado ao Fórum Anual de Pesquisa em Cirurgia que já compartilhava historicamente com a SOBRADPEC a discussão e apresentação dos trabalhos de Pesquisa em Cirurgia.

Consolidava-se praticamente com chave de ouro em nossa gestão a união verdadeira e profícua de nossas Entidades em prol da cirurgia brasileira.

Seja bem vinda a SOBRADPEC ao CBC, a Casa do Cirurgião Brasileiro.

Que a Acta Cirúrgica Brasileira seja também em futuro próximo o Surgical Forum of the Brazilian College of Surgeons.

Vida longa as nossas Sociedades. 